\section{$\underset{\substack{\text { hommes } \\ \text { \& migrations }}}{ }$}

\section{Hommes \& migrations}

Revue française de référence sur les dynamiques

migratoires

1333 | 2021

L'enfance en exil

\title{
Amin Maalouf, Nos frères inattendus
}

Paris, Grasset, 2020, 336 p., $22 €$.

\section{Mustapha Harzoune}

\section{(2) OpenEdition}

\section{Journals}

\section{Édition électronique}

URL : https://journals.openedition.org/hommesmigrations/12775

DOI : 10.4000/hommesmigrations. 12775

ISSN : 2262-3353

\section{Éditeur}

Musée national de l'histoire de l'immigration

\section{Édition imprimée}

Date de publication : 1 avril 2021

Pagination : 224-225

ISBN : 978-2-919040-55-1

ISSN : $1142-852 X$

\section{Référence électronique}

Mustapha Harzoune, « Amin Maalouf, Nos frères inattendus », Hommes \& migrations [En ligne], 1333 | 2021, mis en ligne le 01 avril 2021, consulté le 26 juillet 2021. URL : http://journals.openedition.org/ hommesmigrations/12775; DOI : https://doi.org/10.4000/hommesmigrations.12775 


\section{Nos frères inattendus}

Amin Maalouf, Paris, Grasset, 2020, 336 p., $22 €$.

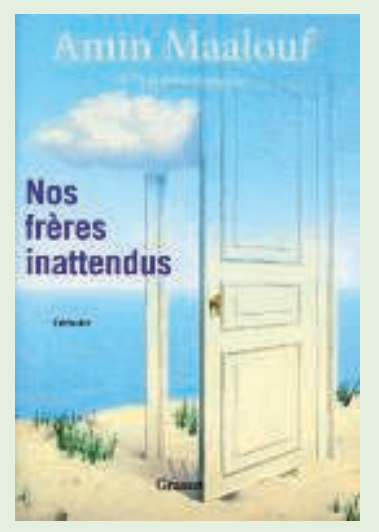

Osons le dire, ce n'est pas le plus réussi des romans du grand et indispensable Amin Maalouf. Mais comme l'écrivain a du talent, il emporte son lecteur, ne serait-ce que par le fond de son propos: la crise de civilisation que l'humanité traverse et, ce vers quoi ses aveuglements conduisent: sa probable extinction. Avant d'être un récit sinuant entre journal, polar, science-fiction, histoire d'amour, Nos frères inattendus appartient à la veine réflexive, philosophique de l'auteur (voir Les Identités meurtrières, Le Dérèglement du monde, Le naufrage des civilisations). Amin Maalouf interpelle ses contemporains sur le devenir du monde.

Le récit court sur un mois. Dans ce laps de temps, "une tragédie vient de se produire»: "Qui conclura nos quelques milliers d'années d'histoire. Qui fera tomber le rideau final sur nos vénérables civilisations. Et qui, incidemment, nous fera tous périr. Ce soir même. Ou peut-être demain aux aurores... » De quoi s'agit-il? Le monde entier est à l'arrêt, tout y passe:

électricité, téléphone, ondes, Internet, avions cloués au sol, États paralysés. Un confinement... numérique et communicationnel imposé à l'humanité. Plus de connexions! Plus de réseaux! Faut-il y voir la main d'une puissance ennemie ou d'un groupe terroriste qui aurait provoqué «une apocalypse atomique»? Non. Alors, quoi?

Alec, le narrateur retiré sur une île inhabitée, "Antioche», la plus petite de l'archipel des «Chirons» sur l'Atlantique, tient le journal des événements. Il y était seul, jusqu'à ce qu'une voisine, associable et misonéiste, vienne s'y installer. Elle se prénomme Ève et est l'auteure d'un retentissant roman, au titre «prémonitoire et visionnaire»: L'avenir n'habite plus à cette adresse. La rencontre sera glaciale. La menace d'une «mort universelle» rapprochera les deux solitaires.

Alec observe, note. Il est en communication avec un ami, Moro, conseiller à la Maison Blanche. Autant dire qu'entre Ève - et oui! -, Moro et ce qui se passe sur l'archipel, il est aux premières loges. Alors il faut imaginer, non pas une puissance ennemie, non pas (encore) l'auto anéantissement de l'humanité, mais l'irruption dans la (mauvaise) marche du monde et de la civilisation d'une organisation extérieure, supérieurement intelligente, pour justement... éviter à l'humanité «un cataclysme planétaire». L'organisation mystérieuse, Les amis d'Empédocle, et ses membres, portent des noms grecs: Démosthène ou Agamemnon. Ils se réclament du «miracle athénien», eux, "avaient compris que leur civilisation allait faire naufrage, et qu'il fallait, coûte que coûte, préserver les idéaux qu'elle portait. Alors ils sont partis [...] en emportant avec eux, dit la légende, "que le contenu de leurs âmes"». Une fable raconte qu' « Un jour, il y a très longtemps, l'humanité s'est divisée. Certains sont partis, comme des émigrés qui seraient allés bâtir une cité nouvelle. Les autres sont restés. Depuis, il y a deux humanités parallèles. L'une vit dans la lumière, mais elle est porteuse d'ombre. L'autre vie dans l'ombre, mais elle est porteuse de lumière... ». «Des émigrés» donc... 
Tout cela métamorphose Ėve: «Je bois et je me réjouis parce que les hommes ont enfin trouvé leurs maitres! Je bois aux amis d'Empédocle! Toute l'arrogance des hommes est à terre!»

Amin Maalouf joue avec les codes de la science-fiction pour dire le réel, décrire ces craintes qui pointent: est-ce que «cet oxygène qui s'engouffrait dans mes poumons ne portait pas les particules de mort»? La Nature elle-même ne deviendrait-elle pas une «menace»? Face aux Amis d’Empédocle, la civilisation bat de l'aile, perd son statut. Ces Frères inattendus sont sortis de l'ombre pour remettre la vie au cœur des valeurs de l'humanité. Seront-ils entendus? "On sous-estime toujours chez les hommes leur désir d'aveuglement. » Même Alec, agacé de voir sa civilisation comme colonisée, rejoint Ėve: «Certains soirs, il m'arrive de trinquer avec elle à l'anéantissement de notre civilisation ventripotent et arrogante, si manifestement déboussolée et cependant persuadée d'avoir toujours raison. » M. $\mathrm{H}$. 